\title{
An Experimental Study to Evaluate the Effects of Adenosine on Intraocular Pressure in Conscious Albino Rabbits
}

\section{Rashmi Shrestha ${ }^{1}$, Anjan Khadka ${ }^{1}$, Nishith Singh ${ }^{2}$}

${ }^{1}$ Department of Pharmacology, Nepalese Army Institute of Health Sciences, Kathmandu, Nepal.

${ }^{2}$ Department of Pharmacology, Armed Forces Medical College, Pune-40, India.

\section{ABSTRACT}

Introduction: Glaucoma is a common problem globally which can lead to irreversible blindness. It is characterized by progressive optic nerve damage. Though its definition doesn't include elevated intraocular pressure but it is known that elevated intraocular pressure is the main culprit behind development of glaucoma. There are various medical and surgical treatment for glaucoma but none are without risk. None of the existing modalities leads to desired control of intraocular pressure and combined approach is needed for the treatment. The study is aimed to evaluate the activity of adenosine, a vasoactive agent, on intraocular pressure in rabbits as the search of newer agents for treatment and prevention of glaucoma. Methods: The study was carried out in albino rabbits using two experimental models viz. water loading model (acute) and steroid induced model (chronic) to induce glaucoma. Intraocular pressure lowering effects of adenosine was studied in both models. IOP was measured with Schiotz tonometer. The intraocular pressure measurement was converted in to $\mathrm{mm}$ of $\mathrm{Hg}$ by using a IOP conversion chart. Results: Adenosine significantly prevented the acute rise in intraocular pressure in water loading acute model of glaucoma and significantly reduced intraocular pressure in chronic dexamethasone induced glaucoma model. The maximum mean difference in IOP between control and adenosine treated eyes were $15.29 \%$ in intragastric tap water loading model. The maximum IOP reduction was 33.52\% in chronic model induced by dexamethasone $(0.1 \%)$. Conclusion: Adenosine significantly prevented the acute rise in intraocular pressure in water loading acute model of glaucoma and significantly reduced intraocular pressure in chronic dexamethasone induced glaucoma model. The maximum mean difference in IOP between control and adenosine treated eyes were $15.29 \%$ in intragastric tap water loading model. The maximum IOP reduction was $33.52 \%$ in chronic model induced by dexamethasone $(0.1 \%)$.

Keywords: adenosine; glaucoma; intraocular pressure; rabbit

\section{INTRODUCTION}

Glaucoma is one of the leading cause of irreversible blindness throughout the world. According to the WHO statistics (1995), it indicates that glaucoma accounts for $13.5 \%$ of global blindness ${ }^{1}$. Glaucoma is a group of conditions in which there is a progressive optic neuropathy with development of associated

Correspondence: Rashmi Shrestha, Nepalese Army Institute of Health Sciences, Kathmand u, Nepal. Email: simhsarinchad@live.com 
characteristic visual field deficits. By definition, it does not include elevated intraocular pressure (IOP) but it is known that elevated IOP is the key risk factor in the development of glaucoma ${ }^{2}$, 3. Raised IOP contributes to the optic nerve damage directly due to pressure effect and indirectly by reducing the blood supply to the optic nerve head to cause ischemia. One would therefore predict that the ideal drug to treat glaucoma would be a substance that lowers IOP, facilitates blood flow to the optic nerve head to prevent ischemia and neural cell death. Different studies show that adenosine exert neuroprotection in the retina along with reducing IOP but the results are inconclusive $e^{4-7}$.

The available treatment modalities for ocular hypertension or glaucoma are pharmacological, laser and surgery ${ }^{1,2}$. These modalities have their own advantages and disadvantages. Considering the patient compliance, cost effectiveness and inherent risk of surgical management, pharmacological approach to reduce IOP appears to be the first choice of treatment. None of the existing agents singularly leads to adequate control of IOP. The search for newer agents to treat glaucoma is an overwhelming clinical necessity.

The models of glaucoma in rabbits are well validated for their clinical correlation and have been used in numerous studies since their discovery ${ }^{8}, 9$.The field of glaucoma has not seen a new class of drugs since prostaglandin analogues was introduced more than a decade ago. Acknowledging that much research still needs to be done for other pharmacological options using different mechanism. In view of the above, the study was aimed to investigate the IOP reducing activity of adenosine in experimentally induced glaucoma model in rabbits.

\section{METHODS}

Healthy adult albino rabbits (New Zealand strain) of either sex, weighing $2-2.5 \mathrm{~kg}$, housed in clean metallic cages in the standard laboratory conditions with free access to food and water ad-libitum were used in the study after obtaining approval from Institutional Animal Ethical Committee (IAEC).

Drugs and chemicals used were:-

1. Adenosine ampoule $(3 \mathrm{mg} / \mathrm{ml})$ :It was diluted in normal saline to prepare a solution of $1 \mathrm{mg}$ per $\mathrm{ml}(0.1 \%)$ for topical use.

2. Dexamethasone phosphate vial $(4 \mathrm{mg} / \mathrm{ml})$ : It was diluted in normal saline to prepare a solution of $1 \mathrm{mg}$ per $\mathrm{ml}(0.1 \%)$ for topical use.

3. Tap water was used to induce acute model of glaucoma.

4. Normal saline $(0.9 \% \mathrm{NaCl})$ was used as control.

Instrument used was:-

1. Schiotz tonometer (Figure 1).

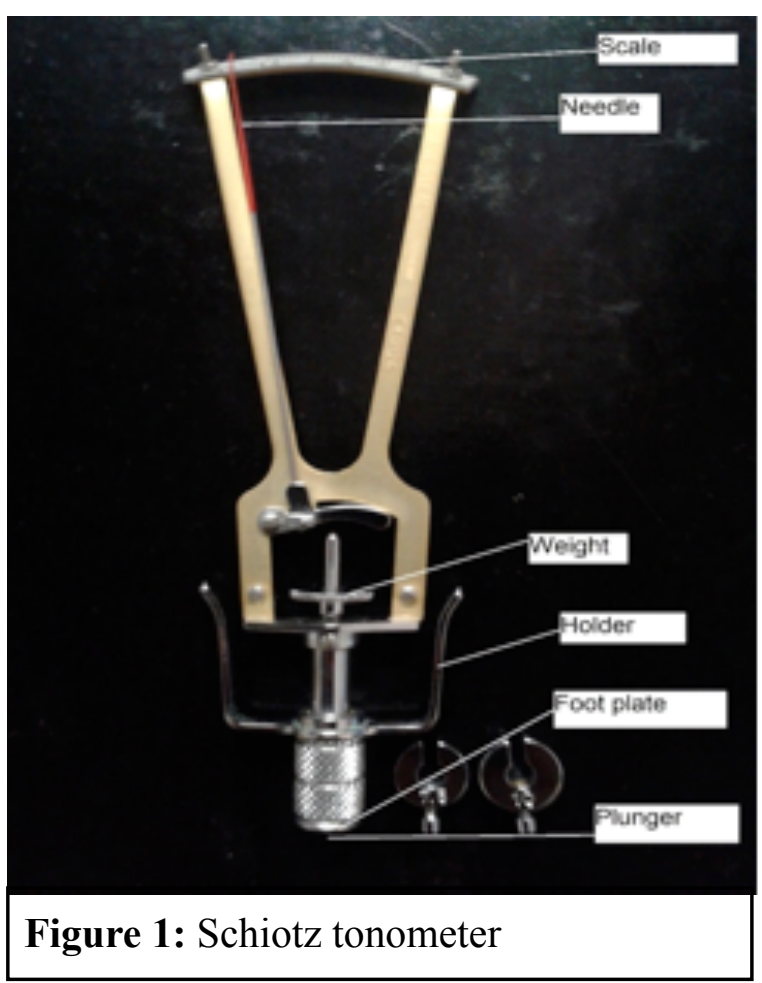


Others instruments used were :-

1. Infant feeding tube of size 4-6 FG: It was used for intragastric tap water administration to rabbit for induction of acute model of glaucoma.

2. Rabbit restrainer: Steel rabbit restrainer was used to restrain the rabbit.

3. Eye dropper: It was used to instill the drugs topically.

4. Syringes: They were used to load water in infant feeding tube to induce acute model of glaucoma.

Models used in the study were:-

1. Water loading model: This is the acute model of glaucoma which is widely used. It was established by Sugiyama et al. In this method, the changes in IOP are temporary. Intragastric water administration leads to reduction in blood osmolarity. This reduction creates an osmotic gradient between blood and aqueous humor and thus a passive flow of water into the eye. Also, there is a decrease in the outflow facility of the aqueous humor likely due to a mechanical obstruction of the outflow by hydration of trabecular meshwork cells $^{10,11}$.

2. Steroid induced model: This is the chronic model of glaucoma which has been used in several studies. The amount of elevation of IOP in rabbits treated with dexamethasone is variable and appears to be age-related. The changes in the aqueous outflow pathway in dexamethasone-treated eyes may be important factors for the development of dexamethasoneinduced ocular hypertension in the rabbit ${ }^{12}$. The mechanism of corticosteroid-induced ocular hypertension is increased aqueous outflow resistance ${ }^{13}$. The precise mechanism of how steroids cause elevation in IOP is not known.

Procedure: The IOP lowering effect of the drugs were studied in 10 rabbits for each model. The right eye of animals was instilled with Normal Saline (control eye) and the left eye was instilled with test drug (test eye). Acute model of glaucoma was induced by intragastric tap water administration and chronic model of glaucoma was induced by $0.1 \%$ dexamethasone phosphate. All the eye drops were freshly prepared on the day of experiment and administered using eye dropper. For each application, one drop of the drug solution was instilled in the middle of the inferior cul-de-sac of each eye followed by lid closure $^{13}$. IOP lowering effects of adenosine was studied in both models. IOP was measured every 15 minutes for 75 minutes in both eyes with Schiotz tonometer. A washout period of 1 week was used between the applications of different test compounds in same animal.

The animals were acclimatized for tonometry before the actual study. The instrument was calibrated before each use by placing it on a stainless steel "eye" provided in a tonometer case and checking that the scale reading is 'zero'. The animal was restrained so as to ease the tonometry procedure. The attendant helped to hold the head of rabbit such that the cornea of rabbit's eye was perpendicular to tonometer. Cornea was anesthetized with 2 drops of $2 \%$ lignocaine eye drops. The tonometer tip and footplate were wiped carefully with alcohol swab and allowed to air dry. The rabbit's eye lids were retracted gently with left hand without placing tension on the globe. The footplate of tonometer was placed directly over cornea by holding the handle of tonometer with 
right hand. The handle of tonometer was lowered to a position midway between the top and footplate such that the instrument works independently by its own weight. The reading on the scale was recorded as soon as the needle became steady. The recording of IOP was started with 5.5 gram weight however if the reading was less than 4 then additional weight was added to the plunger to make it 7.5 gram or 10 gram as indicated ${ }^{14,}{ }^{15}$. The IOP measurement was repeated for three consecutive reading and the average reading and the plunger weight was converted in to IOP in $\mathrm{mm} \mathrm{Hg}$ by using a IOP conversion chart ${ }^{14}$ (Figure 2). Antibacterial (ciprofloxacin) eye drops was instilled after procedure to prevent eye infection.

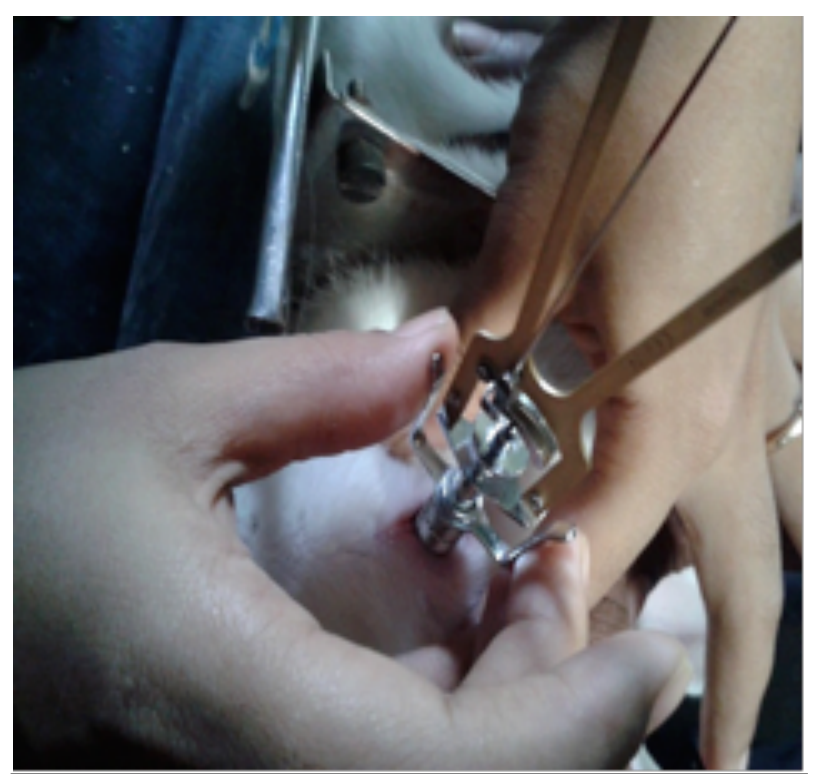

Figure 2: Technique of Schiotz tonometry in rabbit's eye

Results were expressed as mean \pm SEM (standard error of mean). Statistical analysis was done by paired student's t-test. P values < 0.05 were considered statistically significant. The effect of each drug and vehicle was calculated as the difference in IOP $(\triangle \mathrm{IOP}=\mathrm{IOP}$ in test eye - IOP in control eye). The percentage of IOP reduction was defined as
Table 1: Effect of adenosine $(0.1 \%)$ on IOP in water loading induced acute glaucoma model in albino rabbits. $* \mathrm{P}$ value $<0.05$, Change in IOP $\%=($ IOP of treated eye - IOP of control eye)/ IOP of control eye $\mathrm{x} 100$

\begin{tabular}{|c|c|c|c|}
\hline \multirow{2}{*}{$\begin{array}{l}\text { Time } \\
\text { (min) }\end{array}$} & \multicolumn{2}{|c|}{ IOP (mm Hg) } & \multirow{2}{*}{$\begin{array}{l}\text { Change in } \\
\text { IOP }(\%)\end{array}$} \\
\hline & Control & Test & \\
\hline 0 & $13.32 \pm 1.10$ & $13.32 \pm 1.62$ & 0 \\
\hline 15 & $17.58 \pm 1.06$ & $15.49 \pm 1.28 *$ & -11.89 \\
\hline 30 & $22.03 \pm 1.01$ & $18.75 \pm 1.72 *$ & -14.89 \\
\hline 45 & $25.97 \pm 0.81$ & $23.13 \pm 1.47^{*}$ & -10.94 \\
\hline
\end{tabular}

\section{RESULTS}

Effect of adenosine $(0.1 \%)$ on water loading induced acute glaucoma model: Adenosine prevented a short term rise in IOP significantly in comparison to control eye. The rise in IOP in adenosine treated eye was significantly less in comparison to control from 15 minutes to 75 minutes after water loading. The maximum mean difference in IOP between control and adenosine treated eye was $15.29 \%$ at 60 minutes (Table 1).

Effect of adenosine $(0.1 \%)$ on Dexamethasone induced chronic glaucoma model: Adenosine decreased IOP significantly in comparison to control eye. The reduction in IOP by adenosine $(0.1 \%)$ was significant from 15 minutes to 75 minutes in comparison to control. The maximum reduction in IOP was $33.52 \%$ at 75 minutes after adenosine $(0.1 \%)$ eye drop instillation (Table 2).

\section{DISCUSSION}

Adenosine significantly prevented the acute rise in IOP in tap water loading acute model of glaucoma. Similarly adenosine $(28.82 \pm 0.78$ to $19.16 \pm 0.86)$ produced significant reduction in 
Table 2: Effect of adenosine $(0.1 \%)$ on IOP in dexamethasone induced chronic glaucoma model in albino rabbits. $* \mathrm{P}$ value $<0.05$, Change in IOP $\%=($ IOP of treated eye - IOP of control eye)/ IOP of control eye x 100

\begin{tabular}{|l|r|r|r|}
\hline $\begin{array}{l}\text { Time } \\
(\text { min) }\end{array}$ & \multicolumn{2}{|c|}{ IOP $(\mathrm{mmHg})$} & \multicolumn{1}{c|}{$\begin{array}{c}\text { Change in } \\
\text { Coptrol }\end{array}$} \\
\hline 0 & $29.37 \pm 0.69$ & $28.95 \pm 1.17$ & 1.43 \\
\hline 15 & $29.38 \pm 0.75$ & $28.03 \pm 0.83^{*}$ & 4.59 \\
\hline 30 & $28.91 \pm 0.81$ & $24.26 \pm 0.97^{*}$ & 16.08 \\
\hline 45 & $28.87 \pm 0.85$ & $21.65 \pm 0.51^{*}$ & 25.01 \\
\hline 60 & $28.87 \pm 0.85$ & $20.54 \pm 1.24^{*}$ & 28.85 \\
\hline 75 & $28.82 \pm 0.78$ & $19.16 \pm 0.86^{*}$ & 33.52 \\
\hline
\end{tabular}

IOP in chronic dexamethasone induced glaucoma model. The maximum mean difference in IOP between control and adenosine treated eyes were $15.29 \%$ in intragastric tap water loading. The maximum IOP reduction was $33.52 \%$ in chronic model induced by dexamethasone $(0.1 \%)$. This study supports the few other studies which reported the reduction in IOP by adenosine ${ }^{13}, 17,18$. In rabbits, the activation of adenosine $A_{1}$ receptor lowers IOP ${ }^{17,}{ }^{18}$. Few studies also suggest the involvement of adenosine $\mathrm{A}_{2 \mathrm{a}}$ receptor in reduction of intraocular pressure ${ }^{19-21}$. The mechanism of action of adenosine in lowering IOP is not clearly understood but few probable mechanisms are as follows:

1. It reduces IOP by early reduction in aqueous flow followed by a subsequent increase in outflow facility ${ }^{22}$.

2. $A_{1}$ adenosine receptors stimulation in trabecular outflow pathway enhances release of matrix metalloproteinase from trabecular meshwork cells which reduces resistance to outflow of aqueous humor to lower IOP ${ }^{23}$.
3. The oculohypotensive effect of $A_{1}$ receptor agonist is more likely to be due to an effect in post junctional receptors because activation of this receptors suppresses stimulated cyclic adenosine monophosphate (cAMP) accumulation $^{22,24}$.

\section{CONCLUSION}

This study demonstrates that the adenosine prevents the rise in IOP in acute models of glaucoma induced by intragastric tap water loading and reduced IOP in chronic dexamethasone induced glaucoma model. Further experimental and clinical studies are required to be carried out to ascertain clinical efficacy and safety of adenosine, a vasoactive agent, in treatment and prevention of glaucoma.

\section{REFERENCES}

1. Thylefors B, Negrel AD, Pararajasegaram R, et al. Global data on blindness [review]. Bull World Health Org. 1995; 73(1): $115-121 \quad$ PM id:77 04921
PMCid:PMC2486591

2. The Glaucomas. In: Sihota R, Tandon R, editors. Parson's disease of the eye. 21 st Ed. Elsevier, 2011; 280-300.

3. Strouthidis NG, Girard MJ. Altering the way the optic nerve head responds to intraocular pressure-a potential approach to glaucoma therapy. Curr Opin Pharmacol. 2013 Feb; 13(1):83-9. http://dx.doi.org/10.1016/j.coph. 2012.09.001

4. Crosson CE. Adenosine receptor activation modulates intraocular pressure in rabbits.J Pharmacol Exp Ther. 1995 Apr;273(1): 320-6. 
5. Jani A, Goyal R K, Shah G B, Mehta A A. Effect of calcium channel blockers on IOP in rabbits IJPT 2005;4:95-99

6. Lotti VJ, Pawlowski N. Prostaglandins mediate the ocular hypotensive action of the angiotensin converting enzyme inhibitor MK-422(enalaprilat) in African green monkeys. J Ocul Pharmacol 1990;6:1-7. http://dx.doi.org/10.1089/jop.1990.6.1

7. Zurakowski D, Vorwerk CK, Gorla M, Kanellopoulos AJ, Chaturvedi N, Grosskreutz CL et al. Nitrate therapy may retard glaucomatous optic neuropathy, perhaps through modulation of glutamate receptors. Vision Res. 1998 May; 38(10): 1489-94. http://dx.doi.org/10.1016/ S0042-6989(98)00003-0

8. Bouhenni RA, Dunmire J, Sewell A, Edward DP. Animal Models of Glaucoma. J Biomed Biotechnol. 2012:692609. http://dx.doi.org/ $\underline{10.1155 / 2012 / 692609}$

9. T. O. McDonald, J.W. Hodges, A.R. Borgmann, F. E. Leaders. The WaterLoading Test in Rabbits. A Method to Detect Potential Ocular Hypotensive Drugs. Arch Ophthalmol. 1969; 82(3):381-384. http://dx.doi.org/10.1001/archopht. $\underline{1969.00990020383017}$

10. Srivastava S. Antiglaucoma Drugs. In: Gupta SK, ed. Drug Screening Methods, 2nd Ed, Jaypee: 2009; 273-281.

11. Van Bijsterveld OP, Van Loenen AC, Ten Ham M. The effect of hypotensive drugs on the intraocular pressure after water loading in rabbits. Doc Ophthalmol 1981; 52:189-198. http://dx.doi.org/10.1007/ BF01675205
12. Knepper PA, Collins JA, Frederick R.Effects of dexamethasone, progesterone, and testosterone on IOP and GAGs in the rabbit eye. Invest Ophthalmol Vis Sci. 1985 Aug; 26(8):1093-100.

13. Jose' M, Juan S and Jose S. The Effect of Topical Diltiazem on the Intraocular Pressure in Betamethasone-Induced Ocular Hypertensive Rabbits J PharmacolExpTher. 1998; 284:278-282.

14. Allingham RR, Damji K, Freedman S, Moroi SE, Rhee DJ. Intraocular pressure and tonometry. In: Allingham RR, Damji KF, Freedman S, Moroi SE, Rhee DJ, eds. Shields Textbook of Glaucoma. $6^{\text {th }}$ ed. Philadelphia: Lippincott Williams \& Wilkins; 2011:25-9.

15. KönigHLE.Tonometry in general practice-its use in early detection of primary openangle glaucoma. S Afr Med J. 1986 Mar 1; 69(5):309-11.

16. Ota $\mathrm{T}$, Murata $\mathrm{H}$, Sugimoto E, Aihara $\mathrm{M}$, Araie M. Prostaglandin analogues and mouse intraocular pressure: effects of tafluprost, latanoprost, travoprost, and unoprostone, considering 24-hour variation. Invest Ophthalmol Vis Sci. 2005 Jun; 46(6): 2006-11. http://dx.doi.org/10.1167/iovs. 04-1527

17. Borea PA, Gessi S, Bar-Yehuda S, Fishman P. A3 adenosine receptor: pharmacology and role in disease. Hand Exp Pharmacol. 2009; (193):297-237.

18. Klabaunde R E. Cardiovascular pharmacology concepts. Available from: http://www.cvpharmacology.com/antiarrhy/ adenosine.htm. Last assessed on 23/06/2013. 
19. Crosson CE. Adnenosine receptor activation modulates intraocular pressure in rabbits.J Pharmacol ExpTher. 1995 Apr; 273(1):320-6.

20. Li A, Banerjee, Leung CT, PetersonYantorno K, Stamer WD, Civan MM. Mechanism of ATP release, the enabling step in purinergic dynamics. Cell Physiol Biochem. 2011; 28(6): 1135-44.Epub 2011.

21. Konno T, Murakami A, Uchibori T, Nagai A, Kogi K, Nakahata N. Involvement of adenosine $\mathrm{A} 2 \mathrm{a}$ receptor in intraocular pressure decrease induced by 2-(1-octyn-1yl)adenosine or 2-(6-cyano-1-hexyn-1yl)adenosine. J Pharmacol Sci. 2005 Apr; 97(4):501-9. http://dx.doi.org/10.1254/ jphs.FP0040730

22. Crosson $\mathrm{CE}$. Intraocular pressure responses to the adenosine agonist cyclohexyladenosine: Evidence for dual mechanism of action. Invest Ophthalmol Vis Sci. 2001;42:1837-1840
23. Hein TW, Yuan Z, Rosa RH Jr, Kuo L. Requisite roles of $\mathrm{A} 2 \mathrm{~A}$ receptors, nitric oxide, and KATP channels in retinal arteriolar dilation in response to adenosine. Invest Ophthalmol Vis Sci. 2005 Jun; 46(6): 2113-9. http://dx.doi.org/10.1167/iovs. $\underline{04-1438}$

24. Crosson CE, Gray T. Modulation of intraocular pressure by adenosine agonists. J Ocul Pharmacol. 1994;10(1):379-83 http:// dx.doi.org/10.1089/jop.1994.10.379 